\title{
Dystonic Reactions in Children Caused by Metoclopramide
}

\author{
M. CASTEELS-VAN DAELE, J. JAEKEN, P. VAN DER SCHUEREN, A. ZIMMERMAN,
} and P. VAN DEN BON

From the Department of Paediatrics, Academisch Ziekenhuis, St.-Rafael, Leuven, Belgium

Casteels-Van Daele, M., Jaeken, J., Van der Schueren, P., Zimmerman, A., and Van den Bon, P., (1970). Archives of Disease in Childhood, 45, 130. Dystonic reactions in children caused by metoclopramide. Five cases of alarming dystonic reactions are reported in children receiving a normal dosage of metoclopramide, a new anti-emetic drug. The symptomatology consisted mainly of neck pain, torticollis, retrocollis, oculogyric crisis, and trismus, and patients were admitted with presumed diagnoses of encephalitis, meningitis, and tetanus. After discontinuing the drug, all symptoms disappeared completely.

We believe that metoclopramide should be used with caution in paediatrics and that all doctors should be familiar with its possible bizarre side-effects.

Metoclopramide* is a new antiemetic drug, derived from chlorbenzamide and unrelated to such other anti-emetics as belladonna alkaloids, the phenothiazines, and the butyrophenones. Its pharmacological actions include an inhibition of vomiting probably by a direct central effect at the level of the 'vomiting centre' (Justin-Besançon, Laville, and Thominet, 1964; Justin-Besançon and Laville, 1964; Justin-Besançon, Grivaux, and Laville, 1964). Moreover it accelerates emptying of the stomach possibly by an action on autonomic centres (Jacoby and Brodie, 1967) possibly relieving gastric stasis.

The drug was first introduced into clinical practice in France in 1964 and has been used widely as an anti-emetic and as an adjunct to $x$-ray examinations of the upper alimentary tract (Boisson and Albot, 1966; Grivaux, Cornet, and Wattez, 1964). In paediatrics it has been recommended in drug-induced vomiting, gastro-intestinal diseases, pyloric stenosis, and habit vomiting (Vialatte and Paupe, 1964). It has been available in Britain since 1967 but most descriptions of its use are to be found in the French medical literature. The general conclusion is that metoclopramide is a useful and safe drug. However, Borenstein and Bles (1965) observed extrapyramidal reactions in $25 \%$ of psychiatric patients given high doses of metoclopramide. The British

Received 7 July 1969.

^Maxolon-Beecham; Primperan-Delagrange.
Drug and Therapeutics Bulletin (1967) also warns against a combined use of metoclopramide with phenothiazines or sedatives because of a possis development of dystonia.

We present in this paper 5 case reports of childfet who showed alarming side-reactions during treats ment with a normal dose of metoclopramideo Witzel (1968) recently reported 4 similar cases.

\section{Case Reports}

Case 1. An 11-year-old girl was referred with possible diagnosis of encephalitis. She had always been healthy, but 2 days before admission, she suffered: from a mild enteritis. This condition was treated wite a neomycin preparation and with metoclopramide, three tablets of $10 \mathrm{mg}$. a day. The next day, after total dose of $40 \mathrm{mg}$. of the drug, her neck suddent. became stiff so that she could not move her head. This attack lasted for 2 to 3 minutes and reappeared 3 time in the next 2 hours. Between these episodes the girl was quite normal, though she complained of some pain in her neck.

On admission she was a normal healthy girl (weigh? $41 \mathrm{~kg}$.). There were no abnormal physical signt except for a pronounced motor restlessness, consisting of a continuous moving of her legs and arms. A laboratory investigations were negative; fundoscopso was normal.

After some time she was noticed to stare vacantles and to have attacks of hyperextension of her neck During these attacks, which lasted 2 to 3 minutes and during which consciousness was not lost, she could 
not move her head or eyes downwards. Two hours later she started another episode, during which her head was tilted backwards and laterally to the left. At the same time her eyes were rotated upwards to the left and fixed in that position. She also had slight clonic movements of the left facial muscles. The patient remained perfectly conscious and could, on command, look straight on for a little while. But soon her head was rotated again to the left. She felt some pain at her neck, and on palpation an obvious and painful spasm of the left muscle bundle was observed. This attack lasted 5 minutes and immediately thereafter the patient was again unconcerned and free from pain. However, 20 minutes later the same symptoms reappeared but now with a rotation of the head to the right. After a single injection of ethybenztropine $(5 \mathrm{mg}$.) the patient remained free of these attacks, but the motor restlessness lasted the whole night.

Because of the similarity between these symptoms and the extrapyramidal reactions caused by phenothiazines, we suspected a possible causal relation between metoclopramide and these dystonic reactions. This hypothesis was substantiated by the other cases.

Case 2. A healthy boy, aged 5 years, complained two days before admission of slight abdominal pain. He was given ampicillin and metoclopramide syrup, $5 \mathrm{mg}$., three times a day. The next day, after a total dose of $20 \mathrm{mg}$., he complained of pain at his neck and developed an attack, which was described by his parents as consisting of rigidity and hyperextension of the neck. At the same time his eyes were turned upwards, there was a twitching of the facial muscles, a generalized tremor, and an abundant perspiration. The next day the same attack reappeared and a paediatrician, who noticed trismus, thought of a possible diagnosis of tetanus.

On admission the patient appeared to be a healthy boy (weight $14 \mathrm{~kg}$.) without any abnormal physical signs. All laboratory investigations were normal and the electroencephalogram did not show any signs of active cerebral illness. During the night he again had an attack consisting of hyperextension of the neck and trismus. There was no impairment of consciousness. After discontinuing the metoclopramide no further attacks were observed. Three days later the boy left the hospital and remained well.

Case 3. A boy aged $7 \frac{1}{2}$, weight $26 \mathrm{~kg}$., was seen at our out-patients department because of recurrent torticollis for more than a year. We were told by the mother that this stiff neck always appeared suddenly and disappeared similarly abruptly. During these attacks the head was twisted backwards and towards the right, while the eyes were turned upwards. He remained conscious, but he could not articulate very well. $\mathrm{He}$ was then considerably frightened and cried with pain. These episodes lasted 2 to 3 minutes, reappeared 20 to 30 times a day, and this sequence lasted for 2 to 4 days. The boy was then free of all symptoms for one to two months, but then suddenly the attacks would start again. An observation in a neurology department did not elucidate the origin of this bizarre disease.

Sensitized by our two previous cases, we asked the mother whether her son had been given metoclopramide. We were then told that he suffered from cyclic vomiting and that whenever he started vomiting he received on the first day 1 or 2 injections of metoclopramide, $10 \mathrm{mg}$., followed by a daily dose of 2 tablets of $10 \mathrm{mg}$. The torticollis mostly appeared the second day of his vomiting, thus after one day of therapy. A complete discontinuation of metoclopramide rescued the patient from his distressing symptoms.

Case 4. A girl, aged $8 \frac{1}{2}$ years, while playing, was suddenly deprived of speech, because of stiffness of the tongue After she was brought home she complained of severe pain in her neck. At the same time her head was twisted backwards and to the right. She told her parents that her vision was impaired, and at this stage the parents observed involuntary eye movements, lasting about half a minute. Two further such episodes occurred, during which she complained also of pain in her limbs. The parents stressed that she was fully conscious all the time. On admission the girl (weight $26 \cdot 5 \mathrm{~kg}$.) held her head slightly backwards and to the right, and she complained that movement of the neck and palpation of the neck muscles were painful. Further clinical and neurological examination including an EEG and CSF analysis did not reveal any abnormality. On questioning, it was found that the girl had been taking metoclopramide, $15 \mathrm{mg}$. a day for 3 days. This therapy was interrupted, and she was given $75 \mathrm{mg}$. phenobarbitone. No further episodes occurred.

Case 5. An 11-year-old boy (weight $28 \mathrm{~kg}$.) was given metoclopramide $3 \times 10 \mathrm{mg}$. and oxazepam $1 \times 15 \mathrm{mg}$. a day, because of vague abdominal symptoms, most probably of psychosomatic origin. After treatment for two days, the boy complained of a strange feeling in his throat, and that he could not swallow properly. At the same time, his head was thrown backwards.

On admission there were no abnormal physical signs. The treatment with metoclopramide was discontinued and the patient has remained free of all symptoms since then.

\section{Discussion}

Our first patient raised the suspicion of toxicity to metoclopramide because she developed the extrapyramidal symptoms known to occur after phenothiazines (Ayd, 1961; Cottom and Newman, 1966; Gupta and Lovejoy, 1967). This idea was confirmed by the occurrence of identical dystonic reactions in 4 other patients receiving metoclopramide.

All our 5 patients developed some dystonic reactions and dyskinesia characterized by an abrupt onset of retrocollis, torticollis, facial grimacing, oculogyric crisis, dysarthria, dysphagia, trismus, 
TABLE I

Reactions of Patients to Metoclopramide

\begin{tabular}{|c|c|c|c|c|c|}
\hline Symptoms & Case 1 & Case 2 & Case 3 & Case 4 & Case 5 \\
\hline 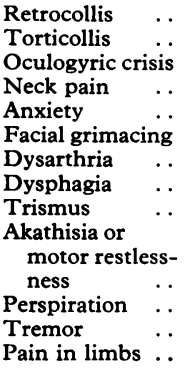 & $\begin{array}{l}+ \\
+ \\
+ \\
+ \\
+ \\
+\end{array}$ & $\begin{array}{l}+ \\
+ \\
+ \\
+\end{array}$ & $\begin{array}{l}+ \\
+ \\
+ \\
+ \\
+ \\
+\end{array}$ & $\begin{array}{l}+ \\
+ \\
+ \\
+\end{array}$ & + \\
\hline
\end{tabular}

or other involuntary muscle movements. These symptoms are summarized in Table I. It shows that the most common symptoms in our patients are retrocollis, neck pain, oculogyric crisis, and torticollis. Metoclopramide appears to affect preferentially the muscles of the neck and the muscles of the eye. The oculogyric crisis begins with a fixed stare for a few moments. Then the eyes are rotated upwards and to the side and fixed in that position. The patient is barely able to move his eyes. At the same time the head is tilted backwards and eventually laterally, the mouth is opened wide and the patient's facial expression suggests pain and often anxiety. These crises in our patients lasted from a few seconds to five minutes and were often described as being very painful. An important feature of these attacks, stressed by all parents, was that the child remained fully conscious. Akathisia or motor restlessness was observed in our first patient: she continuously shifted her legs, was moving from one side to the other, and twisted her fingers. This restlessness lasted for another day after discontinuing the drug, while the dystonic reactions had already subsided. क The reactions occurred in our patients while under treatment with a normal dose according? to the manufacturer's recommendations (Table II). $\overrightarrow{\vec{F}}$ The first four patients did not receive any additional $\stackrel{\text { ? }}{?}$ therapy which could affect the central nervous system. Moreover none of the patients presented $\frac{\bar{\sigma}}{\bar{\omega}}$ an illness which could have sensitized the child to $\vec{\sigma}$ metoclopramide. This suggests that these extra- $\Omega$ pyramidal reactions are not dose-dependent, but क that they are caused by an unusual sensitivity to the $\overrightarrow{0}$ drug. For Case 5 we have to mention that metoclopramide was given in association with a daily $\vec{\omega}$ dose of $15 \mathrm{mg}$. oxazepam. It cannot be excluded that this drug facilitated the untoward reaction to $\frac{\circ}{\circ}$ metoclopramide in this patient.

The extrapyramidal reactions to metoclopramide of appeared soon after starting the treatment. Our $\omega_{0}$ first 3 patients developed their symptoms after $\vec{\omega}$ having received the drug for one day, while in ${ }^{\circ}$ Cases 4 and 5 the dystonic symptoms became 은 apparent after three and two days. All reactions began thus within 72 hours of starting the drug.

Little can be said about the origin of these $\frac{D}{2}$ reactions. We were struck by the fact that they were $\frac{c}{d}$ very similar to the extrapyramidal reactions caused $₹$ by phenothiazines, though metoclopramide $\$ \vec{\theta}$ chemically different from this group.

As to the therapy of these untowards effect we would like to stress the importance of earty recognition and prompt diagnosis. The abrupt onset and the dramatic neuromuscular manifestations can be misinterpreted as encephalitis, tetanus, meningitis, resulting in unnecessary emergency hospitalization, lumbar punctures, or serum therapy. The history of our third patient is most impressive. Presenting a very distressing 'cyclic torticollis' for more than one year, he was seen by several doctors before the reason for his dystonic symptoms was elucidated. The diagnosis may thus be? difficult, unless the physician has a high index of

TABLE II

Dosage of Metoclopramide, and Duration from Time of Administration to Onset of Symptoms

\begin{tabular}{|c|c|c|c|c|c|c|}
\hline Case No. & Age (yr.) & Weight (kg.) & Sex & Reason Drug Taken & $\begin{array}{c}\text { Total Amount Taken } \\
\text { Daily }\end{array}$ & $\begin{array}{l}\text { Duration from First } \\
\text { Administration to } \\
\text { Symptoms (hr.) }\end{array}$ \\
\hline $\begin{array}{l}1 \\
2\end{array}$ & 11 & 41 & $\mathrm{~F}$ & Enteritis & $\begin{array}{l}3 \times 10 \mathrm{mg} . \text { orally } \\
3 \times 5 \mathrm{mg} \text {. orally }\end{array}$ & 26 \\
\hline $\begin{array}{l}4 \\
5\end{array}$ & $\begin{array}{l}8 \frac{1}{2} \\
11\end{array}$ & $\begin{array}{l}26 \\
28\end{array}$ & $\mathbf{M}$ & $\begin{array}{l}\text { Cyclic vomiting } \\
\text { Gastroenteritis } \\
\text { Abdominal pain }\end{array}$ & $\begin{array}{l}1 \text { or } 2 \times 10 \mathrm{mg} . \mathrm{I} . \mathrm{M} \text {. } \\
\text { followed by } 2 \times 10 \\
\text { mg. orally } \\
3 \times 5 \mathrm{mg} . \text { orally } \\
3 \times 10 \mathrm{mg} . \text { orally }\end{array}$ & $\begin{array}{l}72 \\
48\end{array}$ \\
\hline
\end{tabular}


suspicion. Once the right diagnosis is made, therapy does not offer any problem: after the drug is discontinued, all the dystonic reactions disappear after some hours. However, the restlessness in Case 1 lasted for another day. In extrapyramidal reactions caused by phenothiazines both cerebral depressant and stimulant drugs can act as antidotes (Cottom and Newman, 1966). Gupta and Lovejoy (1967) treated these cases by intravenous administration of diphenhydramine (Benadryl), and in most of their cases there was a striking response to this treatment. Little is known about the treatment of patients with dystonic reactions caused by metoclopramide. Our first patient responded well to ethybenztropine, and another one to phenobarbitone. But three of them recovered as rapidly without any therapy after the drug was discontinued. Witzel (1968) used barbiturates in his four patients also with good results. Our experience is that the immediate discontinuation of metoclopramide is sufficient and probably the best therapy.

In 4 of our 5 cases, metoclopramide was given for minor gastro-intestinal disturbances. As most of these illnesses do not last long and respond to simple measures, we doubt whether the use of metoclopramide is indicated. The fact that we saw 5 cases over a period of one year suggests that the occurrence of these side-effects may not be uncommon. Metoclopramide should not be used indiscriminately in children, and all doctors should be aware of its puzzling side-effects.

We are very much indebted to Professor P. Denys for his critical advice.

\section{REFERENCES}

Ayd, F. J., Jr. (1961). A survey of drug-induced extrapyramidal reactions. Fournal of the American Medical Association, 175, 1054.
Boisson, J., and Albot, G. (1966). Sur l'intérêt thérapeutique du métoclopramide. A propos de 2,300 observations. Revue critique et indications de son emploi. Cahiers du Collège de Médecine des Hôpitaux de Paris, 7, 45.

Borensteın, P., and Bles, G. (1965). Effets cliniques et électroencéphalographiques du métoclopramide en psychiatrie. Thérapie, 20, 975 .

Cottom, D. G., and Newman, C. G. H. (1966). Dystonic reactions to phenothiazine derivatives. Archives of Disease in Childhood, 41, 551.

Drug and Therapeutics Bulletin (1967). Maxolon. 5, 72.

Grivaux, M., Cornet, A., and Wattez, E. (1964). Le métoclopramide en radiologie digestive. Semaine des Hopitaux de Paris, 40, 2338.

Gupta, J. M., and Lovejoy, F. H., Jr. (1967). Acute phenothiazine toxicity in childhood: a five-year survey. Pediatrics, 39, 771.

Jacoby, H. I., and Brodie, D. A. (1967). Gastrointestinal actions of metoclopramide. An experimental study. Gastroenterology, 52, 676.

Justin-Besançon, L., Grivaux, M., and Laville, C. (1964). Tronc cérébral et physiopathologie digestive. Recherches cliniques et biologiques. Archives des Maladies de l'Appareil Digestif et des Maladies de la Nutrition, 53, 1273.

, and Laville, C. (1964). Action antiémétique du métoclopramide vis-à-vis de l'apomorphine et de l'hydergine. Comptes Rendus des Séances de la Société de Biologie et de ses Filiales, 158, 723.

$\longrightarrow$, , and Thominet, M. (1964). Le métoclopramide et ses homologues. Introduction à leur étude biologique. Comptes Rendus Hebdomadaires des Séances de l'Académie des Sciences, 258, 4384.

Vialatte, J., and Paupe, J. (1964). Applications du métoclopramide aux vomissements du nourrisson et de l'enfant. Semaine des Hôpitaux de Paris, 40, 2367.

Witzel, K. (1968). Extrapyramidal-motorische Störingen bei Kindern als Nebenwirkung der Therapie mit Neuroleptica und dem neuen Antiemeticum Metoclopramid. Archiv für Kinderheilkunde, 177, 277.

\section{Addendum}

Since submission of this paper we have observed two more cases. One of the patients showed the typical dystonic episodes and was sent to the hospital with the presumed diagnosis of tetanus. The second patient presented, in addition to the dystonia, clonic movements of neck and back.

Correspondence to Dr. M. Casteels-van Daele, Department of Paediatrics, Academisch Ziekenhuis, St.-Rafael, Leuven, Belgium. 